\title{
Mobile Based Sharing Class Presentation Display Management
}

\author{
https://doi.org/10.3991/ijim.v14i07.11718 \\ Junrie B. Matias $\left.{ }^{\bowtie}\right)$, Narciso M. Batingal Jr, Alvin Kleen L. Cuasito, \\ Jenifer T. Tumalaytay \\ Caraga State University Main Campus, Butuan City, Philippines \\ jomatiasecarsu.edu.ph
}

\begin{abstract}
In this paper, we present an application that helps the teachers in identifying slow learners in a class; similarly, the system helps slow learners cope up with their fast learner peers. Specifically, we evaluated the development of the Mobile-based Sharing Presentation Display Management to assist the teachers in identifying students that do not understand the topic during lectures. Furthermore, the system automatically collects the students' attendance, allows the learners to interact with each other, learners can ask questions through a messaging facility. At the same time, anonymous to their classmates, they can inform the teacher to discuss the topic further presented in the current slide or to give them some time to process the item. The system was developed using open source technologies and can run on multiple platforms, including Android and Windows. This study found that both students and teachers perceive the use of the system positively, and they considered as advantageous to improve their performance in the class.
\end{abstract}

Keywords - Mobile Learning, Shared Presentation Display, Socket Programming, Web Technologies

\section{Introduction}

The traditional teaching practices gives educators enormous responsibility; in the class, while conversing lessons using whiteboards and image projectors, teachers make sure that the students are paying attention and understand all they taught [1]. Interaction among learners is an essential element of the learning process; consequently, most of the instructional materials and pedagogy are individually-based and student-paced [2]. Students are inclined to learn on their timing, independent of their peers [2], and proceed to another topic and material if a guaranteed proficiency attained. Instead of being a source of new knowledge, the teachers only assist students when needed [3]. However, learning ability varies among students; some learn quickly in little time while others require extra time [4]. Some students may not understand the topic thoroughly and may perceive it differently, and these students know that they are slow learners [5]. Slow learners are regular students and eventually learn if they put extra time and effort 
while fast learners can learn and move faster [6]. Thus, if not given enough time and attention, slow learners were not able to keep up with fast learners.

To offer proper good learning experiences, educators need to be innovative in managing the class [4] and need to understand the difference between individual thinking capabilities [7]. Similarly, in some cases, several teachers were unaware of the quickness or the speed and the way they discuss the lesson that could result in more lessons not entirely understood by several learners in a class, specifically the slow learners. Furthermore, slow learners are often quiet, shy, and may have reduced self-confidence, feel embarrassed to ask questions or clarifications in front of their classmates [8], and these learners exist in almost every class. So far, there are no exiting means in identifying and supporting them [6].

The study [9] suggests that teachers must observe significant scenes and monitor the progress and development of the class and make effective decisions to increase student achievement. Moreover, there are new ways that possibly will help to capture student progress and observation through the use of information and communications technology (ICT) [10]. The rise of ICT services changes the delivery of various fields, such as research, banking, and education [11], [12]. Moreover, the advent of mobile technologies and mobile devices become affordable and customizable [13]. These phenomena created unique methods and approach in education, like mobile learning, blackboard applications, and online and mobile quiz applications [14], [15].

Several works of literature presented the use of ICT, especially mobile technologies, to aid the management and delivery in education. Mulyono [16], developed an app to minimize teachers' absence in the class in a private university in Indonesia. During the implementation, three challenges had surfaced, namely: the processing, reporting, and input operation. However, results show that the teacher's perception of the mobile app's usefulness is positive.

The study [13], revealed that the attitudes towards mobile learning by the students in UAE had improved through the usage of mobile devices, which also affect the intention to use mobile learning in higher education. Similarly, educators have positive attitudes with regards to mobile learning, and results indicate that mobile learning systems can be adopted by all educators regardless of their academic ranks and experience.

Kim and Rha [17] empirically analyzed the factors affecting the adoption of mobile learning in South Korea based on three different consumer groups, namely: the critical adopters, pro-technology, and ambivalent. Their study suggest that compatibility and observability are the most significant factors that affects adoption of mobile learning. Additionally, for the critical adopter and ambivalent groups, resistance is the primary driver on the intention to use mobile learning. At the same time, self-efficacy is the most excellent motivator to adopt mobile learning for the pro-technology group.

The study [18] presented the advantages of mobile computing in learning based on students from three universities across the US. The students' teachers had been using mobile computing to support their learning experience for two semesters. Results show that computing devices had the advantages of accessing information quickly; it gives a variety of ways to learn and enable situated learning.

Mobile technologies can provide new practical experience and training opportunities for a teacher in facilitating knowledge transfer and stimulate thinking in the classroom 
[19]. The current study presents the development and evaluation of the Mobile-based Sharing Presentation Display Management that assists the teachers in identifying students that do not understand the lesson during lectures. Moreover, the system is a voting tool designed to enable the students, especially the slow learners and those students who are hesitant to ask questions to cast a vote to notify their teacher that there are students who do not understand the topic yet. Similarly, the system automatically collects the attendance, allows the learners to interact with each other, permit students to ask questions through a messaging facility while anonymous to their classmates. Lastly, this study documented the structure and development process of the system and explored the perceptions of teachers and students towards the use of the system.

\section{Method}

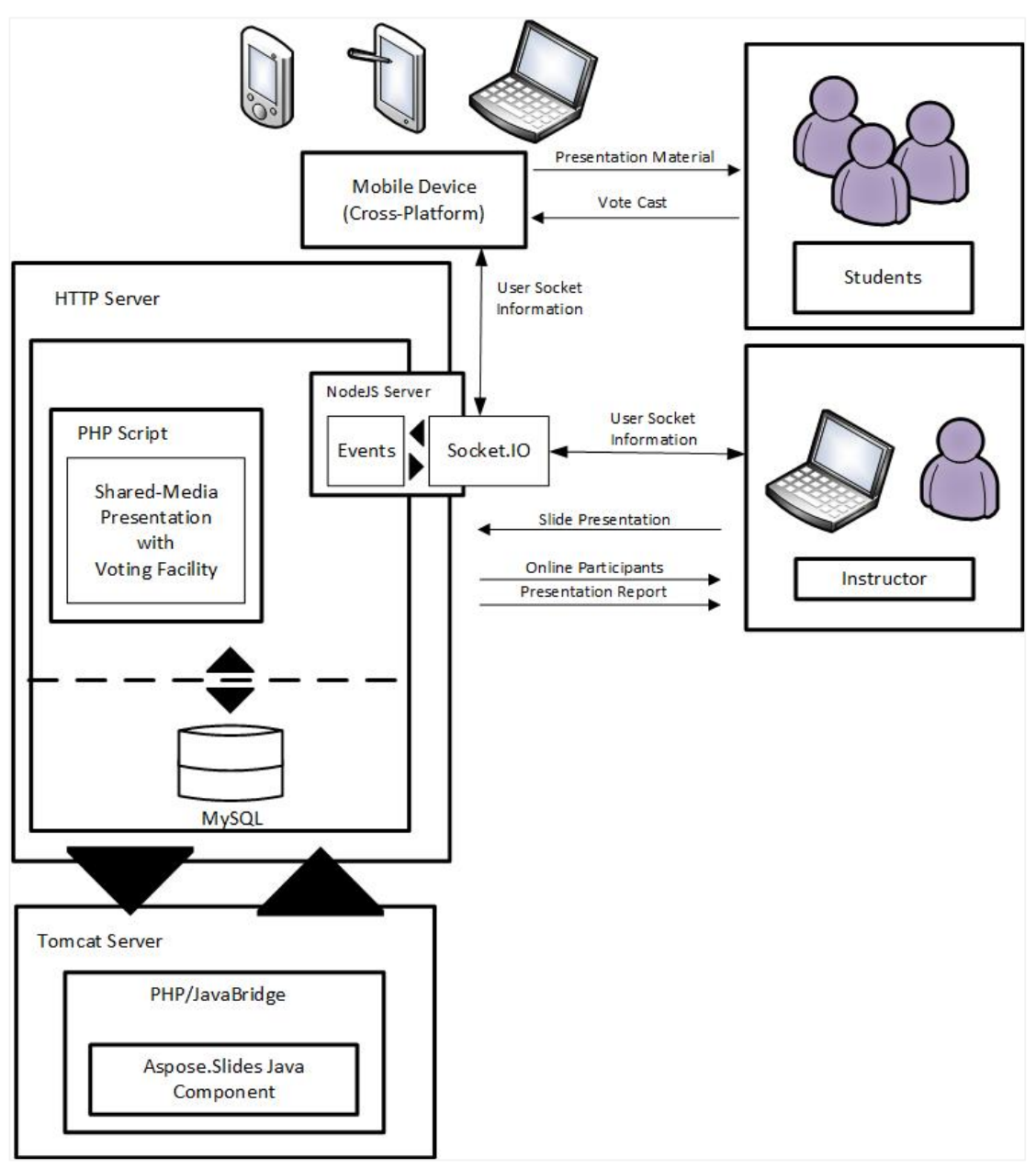

Fig. 1. Architectural Design of the System 
The system designed to conform to multiple platforms, it can provide a matching interface to any mobile devices which allow various display specification. The system can consolidate opinions from the students. It can generate reports and analysis to distinguish if the teaching-learning method used, or the delivery were adequate to the learners. Figure 1 shows the system developed using the various software applications and web-based technologies, including Apache HyperText Transfer Protocol (HTTP) Server, Tomcat Server, Node.js, Android Development tool, Apache NetBeans, and Java.

Utilizing the socket programming approach, different components on the system can communicate over the network - the system comprised of three servers, namely: the Apache HTTP Server, Tomcat Server, and Node.js server. The Apache Server is a general-purpose HTTP server, with the ability to support numerous programming languages like Hypertext Preprocessor (PHP) and Python, server-side scripting, an authentication mechanism, and database support. The Tomcat Server to enable PHP and Java Bridge is used to connect a native PHP script engine with a Java virtual machine. The tomcat server allows java applications to receive the PowerPoint presentation uploaded by the teachers and convert it into image file formats; then, a Java application forward the PowerPoint file to the HTTP server (PHP script) and save the file. The Node.js server provides the system with an event-driven, asynchronous I/O and cross-platform runtime environment.

Furthermore, MySQL, a relational database management system, is used to store all information inputted and generated for/by the system. Lastly, the mobile-client application runs on cross-platform devices. The Node.js server receives client requests, and by utilizing Socket.IO, the presentations are then able to be shared to with the clients' devices.

\section{$3 \quad$ Narrative Development and Findings}

Although designed for mobile devices, the system is also accessible using a desktop computers or laptop that runs on any platforms. Both students and teachers have a unique account and one authorized personnel managing the data for security and confidential purposed.

\subsection{Teacher management page}

Shown in Figure 2 is the interface for the teachers, which contains several menus and functionalities. The teachers can upload a power point presentation for a specific section or group of students. In the navigation panel, the teacher can also check the attendance of the students using the class list option and can view and send messages from/to the students that are accessible in the discussion menu option. A drown-down menu is also available to choose a specific student section for the class, and by clicking the share button, the presentation shared and can be view by the students using their mobile client app. The server IP address and Port where students should connect is visible in the upper right of the page. 


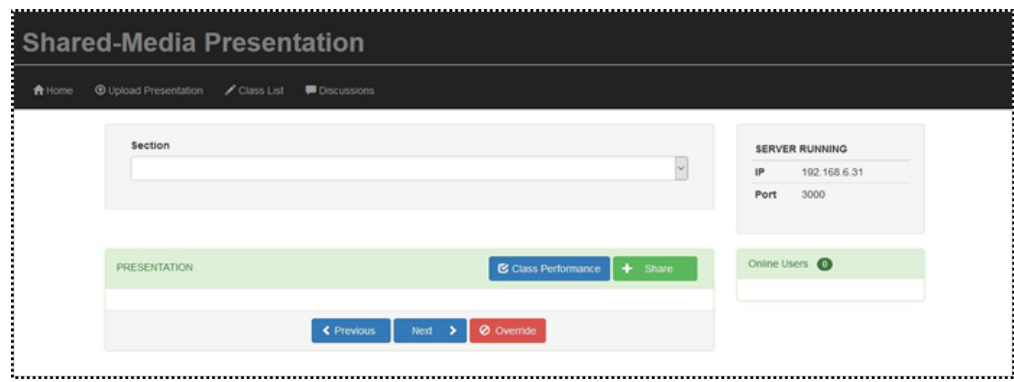

Fig. 2. Interface for the teachers

After the instructor selected and shared the class slide presentation to the students' client app, the presentation displayed in the teachers' presentation windowpane of the main page. The teacher can start the lectures using the slide presentation and provided with three slide control action. First, is the Previous button that allows the teacher to go back to the previous slide. Next is the Next button, which helps the teacher to move to the next slide. However, the system will not allow the slide to move forward if the majority of the student voted to hold the slide. As can be seen on the page (see Figure 3 ), which $75 \%$ of the students voted to proceed to the next slide and $25 \%$ percent voted to hold and requested to discuss the slide further.

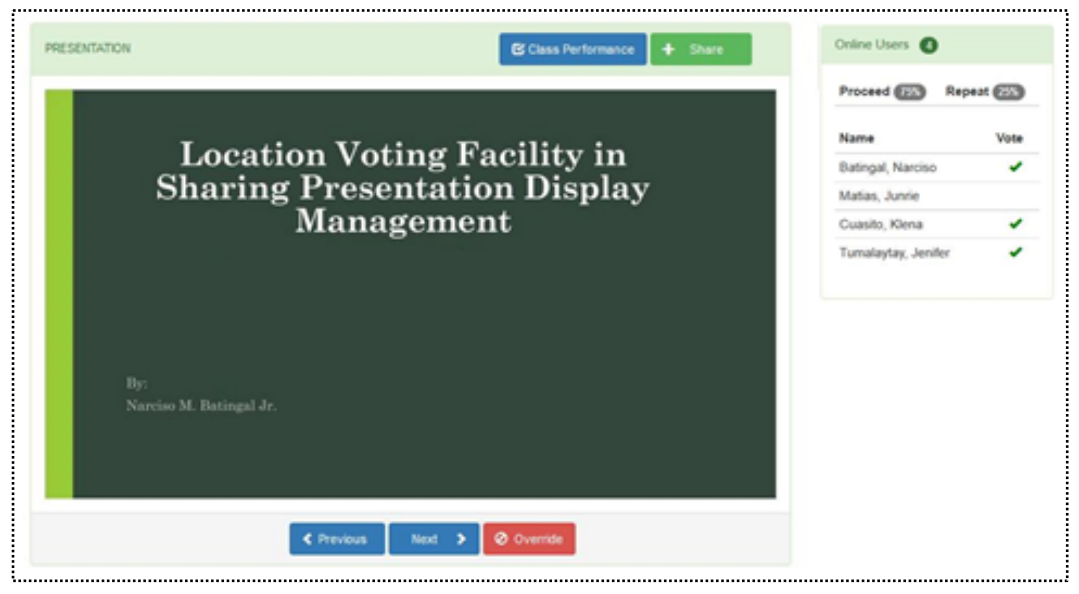

Fig. 3. Server Presentation View

Thus, the presentation proceeds to the next slide if the majority of the students' attendance votes or taps for "Proceed" in their mobile devices. Nonetheless, the teacher is still the master of the class. They can override the control of the presentation using the Override button whenever the teacher decides that the lesson should proceed to the next slide. For the students to pay attention to the class, they are all required to tap for Proceed or Repeat. 


\subsection{Uploading presentation}

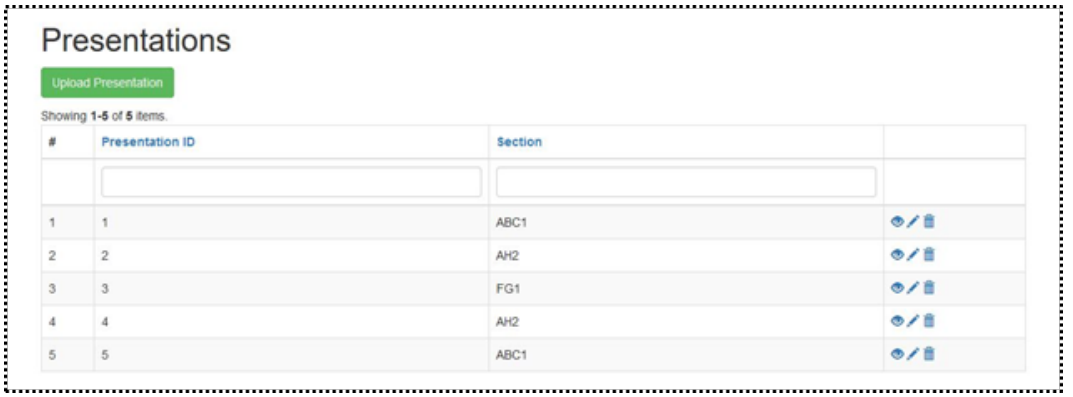

Fig. 4. PowerPoint Presentation Upload Form

The Upload Presentation navigation from the main page will redirect to the page to the upload presentation page shown in Figure 4. On this page, the teacher can upload the presentation to the specific student section, can edit or delete it if needed.

\subsection{Student registration}

The system is part of a more significant project aimed at creating a smart classroom and smart learning technologies. However, the system not yet integrated into the university student information system. For this experiment, each classroom installed with a PC server and a Wi-Fi hotspot. Each PC server is capable enough to serve up to 50 students per class. Furthermore, the teacher manually registers the student using the form shown in Figure 6.

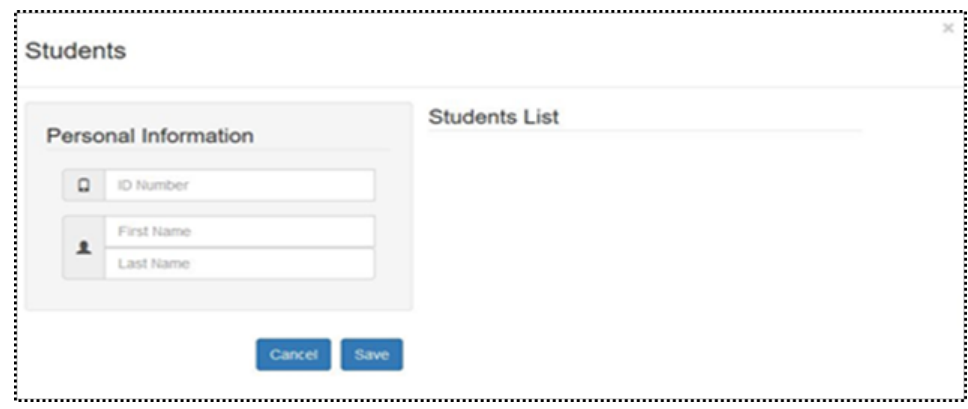

Fig. 5. Student Registration Form

To register a student to the class, the teacher must enter the student ID to the form, and then the system verifies the information and provide the name of the student; hence, all students are pre-registered to the system. However, the teacher must have a copy of the students' master list generated by the university information system as a reference. 


\subsection{Student mobile-client app}

To ensure security and authentication of the students' identity, they required to login through username and password. Students can only login to the presentation session if they are validated and enrolled in the class. To connect, the student must specify the IP address of the server and Port (see Figure 6). After a successful log-in, they can now choose their specific class and access the class presentation shared by their teacher.

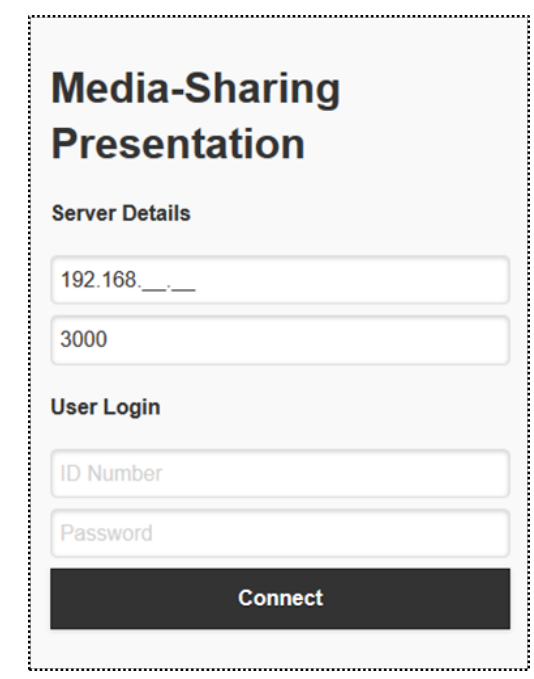

Fig. 6. Student mobile-client app log-in form

Shown in Figure 7 is the main view of the student mobile-client app wherein the slides synchronized with the teacher presentation. The Repeat and Proceed buttons are real-time voting action to inform the teacher whether the learners already understood the topic and ready to proceed to the next slide or to repeat the discussion of the current slide. Moreover, a button is also available on the page menu to access the messaging facility to allow the students to send questions or ask clarifications to the teachers anonymously. A drop-down menu is also accessible on the menu, where the students can able to download the PowerPoint presentation.

Figure 8 shows the time duration, in seconds, of each slide discussed by the teachers wherein the longest length is where the discussion stayed for an extended time to realize the lesson. The report automatically generated every time the presentation and voting of students are completed. The reports saved for the future use of the teachers and to track the slide wherein the learners needed extra time to understand the discussion.

\subsection{Students perception of the system}

A survey conducted to determine the students' perception of the system's usefulness, ease of use, and intention to use at the Caraga State University Ampayon Campus at Butuan City, Philippines. A total of 200 students were randomly selected from different 


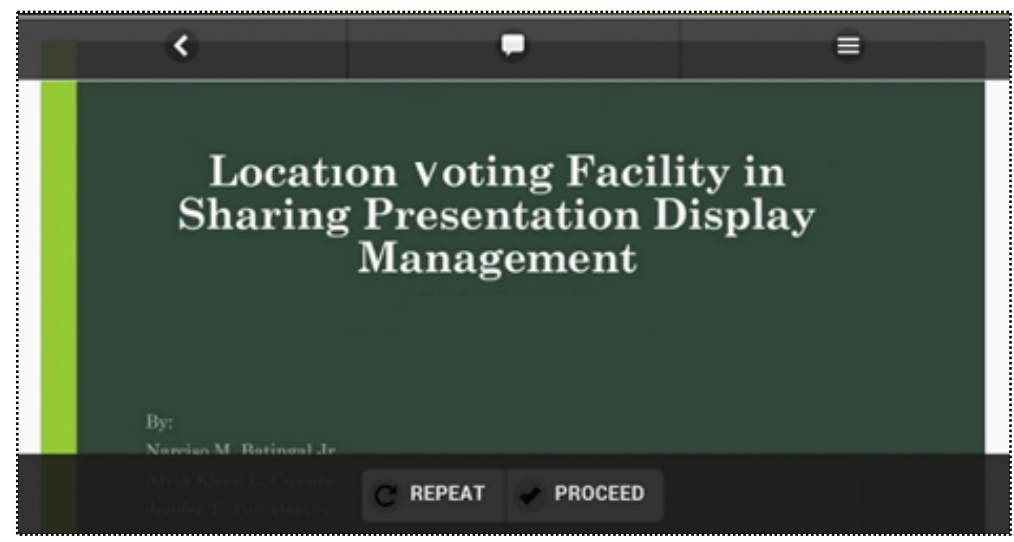

Fig. 7. Student mobile-client app main view

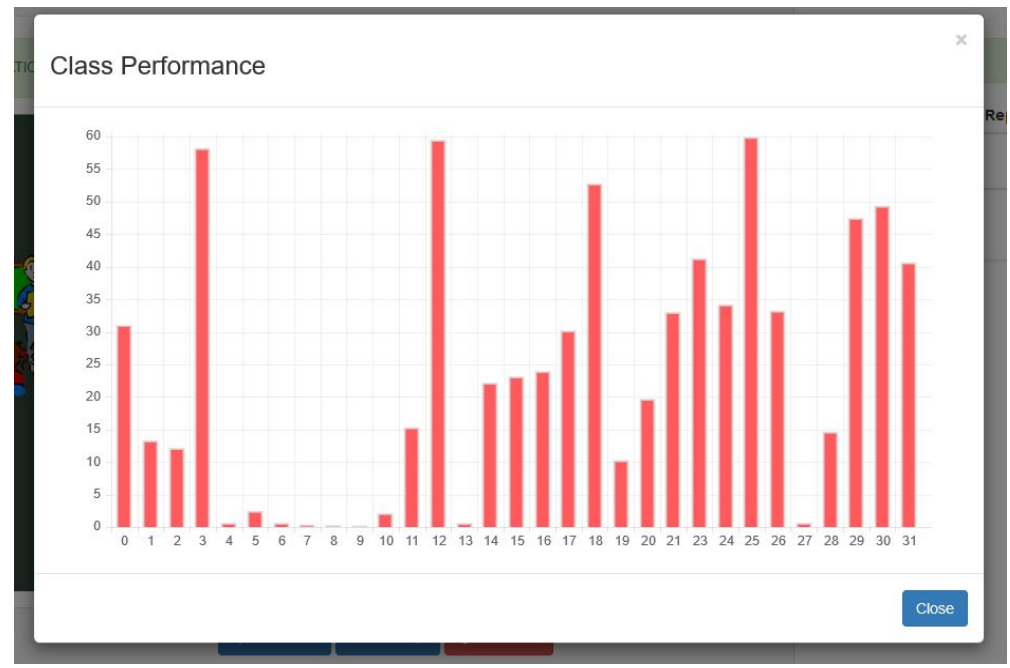

Fig. 8. Duration of the discussion for each slide

colleges and invited to attend a demo class using the system. The students are divided into 4 sections with 50 students each and assigned to the distinct classroom. For demonstration purposes, each class is installed with 1 PC server and wifi to connect the student's mobile app to the server. After the demo class has ended, the student asked to fill the questionnaire.

Moreover, the survey based on three factors, namely: perceived usefulness [20], perceived ease of use [20], and behavioral intention to use [21] shown in Table 1. Shown in Table 1 is the scaling and quantification used for indicators with a numerical rating scale of 1 and verbal description of Strongly Disagree, 2 as Disagree, 3 as Agree and 4 for Strongly Agree. Responses from the students and teachers significantly help the development of the system by aggregating their opinions and views to make improvements. 
Table 1. Scaling and Quantification Used for Indicators.

\begin{tabular}{|c|c|l|}
\hline Numerical Rating & Mean Interval & \multicolumn{1}{c|}{ Verbal Description } \\
\hline 1 & $0-1.49$ & Strongly Disagree \\
\hline 2 & $1.50-2.49$ & Disagree \\
\hline 3 & $2.50-3.49$ & Agree \\
\hline 4 & $3.50-4.00$ & Strongly Agree \\
\hline
\end{tabular}

The items (see Table 2) of the questionnaire are taken from the established works of [20], [21] distributed within the following factors:

1. Perceived usefulness indicates the level of students believes that using the app would enhance their learning performance [22].

2. Perceived ease of use indicates the degree of students believes that using the app will free of effort [22].

3. Behavioral intention to use is the measure of the strength of the students' intention to use the mobile app [22].

In the survey questionnaire, there are six items for perceived usefulness, three items for perceived ease of use, and three items for behavioral intention. Table 2 summarizes the distribution Mean of the surveyed student, which confirms that students agree that the system and the mobile app is useful and could help to increase their performance and productivity in the class.

Further, students also agree that the mobile app is easy to use, the interface is clear and understandable, and the mobile app is user-friendly. Lastly, students also agreed to use the mobile app in the future and would recommend its services to their peers.

Table 2. Distribution of Mean and Verbal Description across Different Indicators

\begin{tabular}{|c|c|c|}
\hline Indicators & Mean & Verbal Description \\
\hline \multicolumn{3}{|l|}{ Perceived usefulness } \\
\hline Using the application would enable you to accomplish tasks more quickly & 2.80 & Agree \\
\hline Using the application would improve your performance in the class & 2.84 & Agree \\
\hline Using the application would increase your productivity in the class & 2.97 & Agree \\
\hline Using the application would enhance your effectiveness in the class & 2.83 & Agree \\
\hline Using the application would make it easier for you to engage in the class & 2.61 & Agree \\
\hline Using the application would enable you to accomplish tasks more quickly & 2.94 & Agree \\
\hline \multicolumn{3}{|l|}{ Perceived ease of use } \\
\hline The mobile application is easy to use & 2.57 & Agree \\
\hline Your interaction with the mobile application is clear and understandable & 2.83 & Agree \\
\hline Overall, the mobile application is user-friendly & 2.75 & Agree \\
\hline \multicolumn{3}{|l|}{ Behavioral intention to use } \\
\hline I intend to use the mobile application in the future & 2.54 & Agree \\
\hline I would like to recommend the services of the mobile application to others & 2.82 & Agree \\
\hline I will use the mobile application frequently in the future & 2.79 & Agree \\
\hline
\end{tabular}




\subsection{Qualitative interviews with the teachers}

Teachers asked about their perception of using the system. The findings from the observation and the interviews with the teachers revealed that they have concerns about the capacity of the PC server to handle and serve a request from multiple mobile-client apps. Teachers A said: 'The system should be implemented in a server having a higher capacity to serve multiple class simultaneously.' (Teacher A)

However, the time when the system tested, it was still on the development and testing phase and not fully implemented, even the data of the students not directly pulled from the university information system.

Teacher B suggested:

If possible, at least the system has an option to add video streaming or audio from the teacher. Because if the system can offer these functionalities, the teacher can now deliver his or her lessons even without physically present in the classroom.' (Teacher B)

Teacher $\mathrm{C}$ added:

'The buttons, navigations, and links are easy to find and very functional, and I found it to be secured, reliable, and user-friendly. However, I experienced the PC server to lagged or frozen when the mobile client-app reached 50.' (Teacher C)

\section{Conclusion}

In the current study, we evaluated the construction of the system and its applicability as an instrument to help the slow learners cope up with the fast learners. Students perceived the use of the mobile app positively, which allow them to inform their teachers that they do not understand the matter during lectures, while anonymous and not getting embarrassed to their fast learner peers. Teachers perceived it also to be useful, especially to the beginners. By allowing the students to stop them from moving to the next item or slide quickly, this mechanism gives them time, and opportunity to make adjustments and identify the learners who are having difficulties in realizing the current topic. Teachers can find the appropriate teaching method and innovate to improve their strategy to help slow learners understand the lesson. However, few concerns arise during the system testing, like the mobile-client app getting a delayed response from the server, and the server sometimes experiences lagging if many requests are coming from the mobile-client app. Further improvement of the system should address these issues; hence, this work is part of a more significant project. Lastly, future works include enhancing the graphical interface, integrate the system to the university information system, and evaluate the system effectiveness of the system with an appropriate acceptance model and a large sample size. 


\section{$5 \quad$ References}

[1] P. Negi, C. J. Rawandale, S. Singh, and S. Priyadarshini, "ICT Method V / S Traditional Method: A Study of Law,” Prestig. Int. J. Manag. IT - Sanchayan, vol. 2, no. 2, pp. 39-48, 2013.

[2] J. D. Basham, T. E. Hall, R. A. C. Jr, and W. M. Stahl, “An Operationalized Understanding of Personalized Learning," vol. 31, no. 3, pp. 126-136, 2016.

[3] J. A. Kulik, C. C. Kulik, and P. A. Cohen, "A meta-analysis of outcome studies of Keller's personalized system of instruction.," Am. Psychol., vol. 34, no. 4, pp. 307-318, 1979. https://doi.org/10.1037/0003-066x.34.4.307

[4] D. Nunan, Collaborative language learning and teaching. Cambridge University Press, 1992.

[5] J. Santrock, Educational Psychology, 5th ed. New York: McGraw-Hill Companies, Inc., 2001.

[6] R. Borah, "Slow Learners: Role of Teachers and Guardians in Honing their Hidden Skills," Int. J. Educ. Plan. Adm., pp. 139-143, 2013.

[7] B. Moeller and T. Reitzes, "Integrating Technology with Student-Centered Learning. A Report to the Nellie Mae Education Foundation.," 2011.

[8] E. J. Esther Lee, "Corrective feedback preferences and learner repair among advanced ESL students," System, vol. 41, no. 2, pp. 217-230, 2013.https://doi.org/10.1016/j.system. $\underline{2013.01 .022}$

[9] M. Kunter, U. Klusmann, and D. Richter, "Professional Competence of Teachers: Effects on Instructional Quality and Professional Competence of Teachers: Effects on Instructional Quality and Student Development,” J. Educ. Psychol., vol. 105, no. 3, pp. 805-820, 2013. https://doi.org/10.1037/a0032583

[10] H. Hassan, R. Mailok, and R. Johan, "UPSI Students' Perceptions on the Use of ICT in Learning: Comparison Between Knowledge Test and Task-based Test on ICT Competency," J. ICT Educ., vol. 2, pp. 55-77, 2015.

[11] UNCTAD, "International Trade in ICT Services and ICT-Enabled Services: Proposed Indicators from the Partnership on Measuring ICT for Development," 2015.

[12] J. A. Landicho, "Voisee Communicator: An android mobile application for hearing-impaired and blind communications," Int. J. Interact. Mob. Technol., vol. 10, no. 4, pp. 26-31, 2016. https://doi.org/10.3991/ijim.v10i4.5859

[13] M. Al-Emran, H. M. Elsherif, and K. Shaalan, "Investigating attitudes towards the use of mobile learning in higher education," Comput. Human Behav., vol. 56, pp. 93-102, 2016. https://doi.org/10.1016/j.chb.2015.11.033

[14] F. Khaddage, W. Müller, and K. Flintoff, "Advancing Mobile Learning in Formal and Informal Settings via Mobile App Technology: Where to From Here, and How?” Educ. Technol. Soc., vol. 19, pp. 16-26, 2016.

[15] A. Shdiafat and R. Obeidallah, "Quiz Tool Within Moodle and Blackboard Mobile Applications," Int. J. Interact. Mob. Technol., vol. 13, no. 8, pp. 32-42, 2019. https://doi.org/ 10.3991/ijim.v13i08.10552

[16] H. Mulyono, "Design and Use of a Mobile Application to Prevent Teachers' Absenteeism in a Higher Education Setting," Int. J. Interact. Mob. Technol., vol. 13, no. 8, pp. 4-15, 2019. https://doi.org/10.3991/ijim.v13i08.10270

[17] H.-J. Kim and J.-Y. Rha, "Predicting the Drivers of the Intention to Use Mobile Learning in South Korea," Int. J. Interact. Mob. Technol., vol. 12, no. 1, p. 116, 2018. https://doi. org/10.3991/ijim.v12i1.7688 
[18] J. Gikas and M. Grant, "Mobile computing devices in higher education: Student perspectives on learning with cellphones, smartphones \& social media," Internet High. Educ., vol. \#19, pp. 13-26, 2013. https://doi.org/10.1016/j.iheduc.2013.06.002

[19] T. K. F. Chiu and D. Churchill, "Adoption of mobile devices in teaching: changes in teacher beliefs, attitudes and anxiety,” Interact. Learn. Environ., vol. 24, no. 2, pp. 317-327, 2016. https://doi.org/10.1080/10494820.2015.1113709

[20] H. Mohammadi, "Social and individual antecedents of m-learning adoption in Iran," Comput. Human Behav., vol. 49, pp. 191-207, 2015. https://doi.org/10.1016/j.chb.2015.03.006

[21] A. Hassanzadeh, F. Kanaani, and S. Elahi, "A model for measuring e-learning systems success in universities," Expert Syst. Appl., vol. 39, no. 12, pp. 10959-10966, 2012. https://doi.org/10.1016/j.eswa.2012.03.028

[22] F. D. Davis, "Perceived usefulness, perceived ease of use, and user acceptance of information technology,” MIS Q., vol. 13, pp. 319-340, 1989. https://doi.org/10.2307/249008

\section{$6 \quad$ Authors}

Junrie B. Matias is an associate professor at the College of Computing and Information Sciences of the Caraga State University - Main Campus in Butuan City, Philippines. He holds a master's and doctor's degree in Information Technology. His research interest includes artificial intelligence, technology adoption, software engineering, and programming languages. He has authored several researches which have been presented in international conferences and has several publications under his name. jbmatias@carsu.edu.ph

Narciso M. Batingal Jr. is a BS Information Technology graduate at Caraga State University, Butuan City, Philippines last 2016. Currently, he is working as software developer at Department of Science and Technology - Caraga.

Alvin Kleen L. Cuasito is a BS Information Technology graduate at Caraga State University, Butuan City, Philippines last 2016. Currently, he is working as support staff for administrative services at Department of Science and Technology - Caraga.

Jenifer T. Tumalaytay is a BS Information Technology graduate at Caraga State University, Butuan City, Philippines last 2016. Currently, she is working as project assistant for Small Enterprise Technology Program at Department of Science and Technology - Caraga.

Article submitted 2019-09-21. Resubmitted 2020-01-12. Final acceptance 2019-12-23. Final version published as submitted by the authors. 